\section{Effects of auditory prechoice stimulation on visual exploratory choice*}

\author{
D. E. BERLYNE \\ University of Toronto, Toronto 181, Ont., Canada
}

Previous experiments have shown that Ss are more likely to seek exposure to more complex visual patterns after near darkness or after monotonous overfamiliar stimulation but that this tendency is reduced by a relatively high level of prechoice stimulation (colored pictures). Two new experiments show that the frequency of more complex choices is diminished by exposure to recorded speech but not by exposure to white noise or light music. The results suggest that the level of exteroceptive information processing just before the choice is the operative factor.

In a previous series of experiments (Berlyne \& Crozier, 1971), Ss went through a succession of trials, on each of which they had to choose between pressing a key that exposed a more complex visual pattern on a screen and pressing another key which exposed a less complex pattern. When each choice was preceded by near darkness or by exposure of the two patterns that could follow the choice (and thus soon became monotonously familiar), there was a significant tendency to seek exposure to the more complex pattern. When, however, a colored picture of a tourist attraction was displayed just before the choice, the probability of the response exposing the more complex pattern was significantly reduced. This reduction was more marked when a different colored picture appeared on every trial than when the same colored picture kept on reappearing. A seemingly related phenomenon was observed by Leckart et al (1970). They found time spent exploring fairly complex polygons to increase with the duration of prior "perceptual deprivation."

These experiments left two questions outstanding. It was evident that the probability of choosing to see the more complex pattern depended on the amount of prechoice stimulation, as well as its novelty and possibly its complexity and meaningfulness, but the precise attribute that was responsible remained in doubt. It might have been a matter of how arousing the prechoice condition was or alternately of how much exteroceptive information was taken in just before each choice. Secondly, it was not clear whether visual exploratory choice was affected only by visual prechoice stimulation or by prechoice stimulation regardless of modality.

*This investigation was supported by Research Grant APA-73 from the National Research Council of Canada and by Research Grant $\$ 69-1073$ from the Canada Council. The data were collected by Mary Louise King.

\section{EXPERIMENT 1}

The first experiment was designed to find out whether or not the effects of prechoice stimulation were subject to crossmodality transfer. Three prechoice conditions were used, intended as auditory equivalents of the three conditions used in Experiment 3 of the previous series (Berlyne \& Crozier, 1971). Corresponding to the near darkness, recurrent colored slide, and varying colored slide of that experiment were, respectively, silence, an excerpt from the same piece of music on every trial, and excerpts from different pieces of music on successive trials.

\section{Subjects}

There were 12 male and 12 female Ss drawn from undergraduates enrolled in an introductory psychology course.

Stimulus Material

The postchoice stimulus patterns consisted of the three pairs used in the previous experiments (see Fig. 1).

Prechoice auditory stimulation was taken from a prerecorded stereophonic tape, Capitol Y2P-8612 (Fiesta/Gypsy, played by the Hollywood Bowl Symphony Orchestra, conducted by Carmen Dragon). For the recurrent (R) condition, 50 excerpts from 1 of the 20 pieces on the tape, namely, Glinka's Jota Aragonesa, were used. For the varying (V) condition, excerpts, with randomly selected starting points, were taken from each of the remaining 19 pieces.

$$
\text { Method }
$$

The apparatus and general procedure were the same as in the previous experiments (Berlyne \& Crozier, 1971). Every $S$ went through three phases of 50 trials each, and Stimulus Pairs 1, 2, and 3 (see Fig. 1) were used for the first, second, and third phases, respectively.

On each trial, a buzzer sounded, signaling that $\mathbf{S}$ must press either of the two keys on the table in front of him. Operation of one key caused the more complex pattern of the pair to be exposed on the screen in front of him for $5 \mathrm{sec}$, and operation of the other key exposed the less complex pattern for the same duration. There was a different prechoice condition for each phase, and the six possible permutations of prechoice conditions among phases were each used for two male and two female Ss. For one male and one female $S$ in each of the subgroups formed in this way, the more complex pattern corresponded to the left-hand key in the first phase, the right-hand key in the second phase, and the left-hand key in the third phase. The right-left-right sequence was used for the remaining Ss.

The $\mathrm{S}$ wore high-fidelity earphones throughout the experiment. He was told that music would sometimes be heard before the buzzer sound and sometimes not. Between projections of patterns, the room was in near darkness with dim light coming from the tachistoprojector. There was an interval of $5 \mathrm{sec}$ between the disappearance of a slide and a buzzer sound signaling the next trial. When music was presented, it lasted for $3 \mathrm{sec}$ before the buzzer sound so that 2 sec of silence intervened between the disappearance of the pattern exposed on the previous trial and the beginning of the music.

The prechoice conditions were as follows: $\mathrm{X}$-no sound was delivered through the earphones; $R-a$ different 3 -sec excerpt from one piece on every trial; $\mathrm{V}$-different 3 -sec excerpts on every trial. These were taken from 19 different pieces in random order so that 3 were taken from each of 12

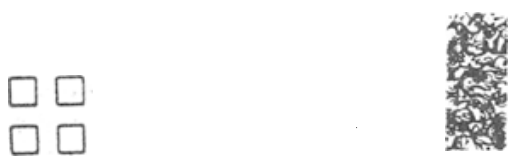

STIMULUS PAIR 1
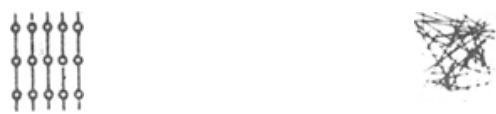

STIMULUS PAIR 2

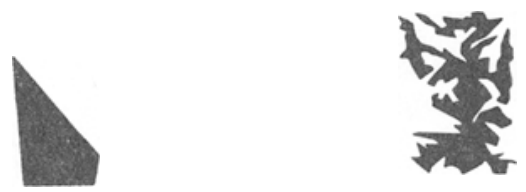

STIMULUS PAIR 3

Fig. 1. Patterns used in Experiments 1 and 2. 
pieces and 2 from each of the remaining 7 .

\section{Results}

Table 1 shows the mean proportion of trials on which the more complex pattern was chosen, as well as the number of Ss making the more complex choice on more than half, half, and less than half of the trials under each of the three prechoice conditions. It will be seen that, according to $t$ tests, more complex choices were significantly more frequent than less complex choices throughout, but the proportion of more complex choices did not vary significantly among the prechoice conditions: $F=1.78, \mathrm{df}=2,44$.

\section{Discussion}

The presence of music before the choice did not, therefore, affect the probability of seeking exposure to a more complex pattern. It is, however, not safe to conclude that auditory stimulation cannot reduce the frequency of more complex choices, as visual stimulation has been shown to do. If the operative factor is an arousing effect of prechoice stimulation, it is conceivable that light classical music of the type presented in this experiment was soothing rather than arousing. If, on the other hand, information intake is the operative factor, the information content of this kind of music, considerable as it is, may well not be processed by $S$ : he is likely to experience it as a continuous relatively undifferentiated flow rather than making any attempt to organize it perceptually and intellectually.

\section{EXPERIMENT 2}

The second experiment examined effects of two further kinds of auditory prechioice stimulation. One was $90 \mathrm{~dB}$ (re .0002 millibar) white noise, which, since it is perceived as a continuous and uniform sound, has no assimilable information content other than the fact of its presence. On the other hand, white noise of comparable intensity or less has been shown to raise arousal, as manifested by effects on skin conductance (Berlyne \& Lewis, 1963), on heart rate and verbal report (Thayer et al, 1970), and on averaged multiple-unit activity in the reticular formation (Podvoll \& Goodman, 1967). It has also been found to produce effects comparable to those of other arousal-raising agents on exploratory behavior (e.g., Berlyne \& Lewis, 1963; Haywood \& Wachs, 1967) and on verbal learning (e.g., McLean, 1969).

The second prechoice condition consisted of excerpts from a recorded story, which can be assumed to have mobilized the information-processing functions that are required for the understanding of spoken language. The excerpts were taken from Spoken Arts

Table 1

Experiments 1 and $2 *$

\begin{tabular}{|c|c|c|c|c|c|c|}
\hline \multirow[b]{2}{*}{$\begin{array}{l}\text { Prechoice } \\
\text { Condition }\end{array}$} & \multicolumn{3}{|c|}{ Experiment 1} & \multicolumn{3}{|c|}{ Experiment 2} \\
\hline & Silence & $\begin{array}{c}\text { Recurrent } \\
\text { Music }\end{array}$ & $\begin{array}{l}\text { Varying } \\
\text { Music }\end{array}$ & Silence & $\begin{array}{l}\text { White } \\
\text { Noise }\end{array}$ & Story \\
\hline Ss with $\mathrm{MC}>.5$ & 19 & 21 & 22 & 18 & 22 & 15 \\
\hline Ss with $\mathrm{MC}=.5$ & 1 & 1 & $\mathrm{o}$ & 2 & 0 & 2 \\
\hline Ss with $\mathrm{MC}<.5$ & 4 & 2 & 2 & 4 & 2 & 7 \\
\hline MC over all Ss & 67 & .71 & .71 & .67 & .69 & .62 \\
\hline$t$ & 5.09 & 6.31 & 6.80 & 5.48 & 6.71 & 3.47 \\
\hline$p$ & $<.001$ & $<.001$ & $<.001$ & $<.001$ & $<.001$ & $<.01$ \\
\hline
\end{tabular}

*MC = proportion of responses exposing more complex pattern

Monaural Tape SA-T-830, containing The Pit and the Pendulum by Edgar Allan Poe, narrated by Alexander Scourby. The last $12 \mathrm{~min} 40 \mathrm{sec}$ of the recording was used. Between two consecutive 5 -sec passages, there was $7.5 \mathrm{sec}$ of the story that $S$ did not hear, so that the excerpts were disconnected. The intensity varied between 80 and $90 \mathrm{~dB}$ most of the time.

\section{Subjects}

There were 9 male and 15 female Ss taken from the same population as those of Experiment 1.

\section{Method}

The apparatus and procedure were exactly the same as those in Experiment 1, except that the white-noise condition ( 2 sec of silence after the disappearance of a slide followed by $5 \mathrm{sec}$ of white noise) and the story condition ( $2-\mathrm{sec}$ period of silence followed by $5 \mathrm{sec}$ of the story) replaced the two music conditions, and consecutive exposures were separated by $7 \mathrm{sec}$ in the silence conditions.

\section{Results}

As Table 1 shows, there was a significant tendency to choose the more complex pattern more often after all three prechoice conditions. However, the proportion of more complex choices was lower after the story condition than after the other two conditions. The means for the three prechoice conditions were significantly different: $F=4.31$, $\mathrm{df}=2,44, \mathrm{p}<.05$. Planned orthogonal contrasts showed that the two prechoice conditions with auditory stimulation did not differ significantly from the silence condition, but the mean number of more complex choices was significantly lower for the story condition than for the white-noise condition: $F=8.39$, $\mathrm{df}=1,44, \mathrm{p}<.01$. The reduction in probability of a more complex choice was comparable with that produced by the recurrent colored slide in Experiment 3 of the previous series (Berlyne \& Crozier, 1971). CONCLUSIONS

Putting together the results of the four experiments of the previous series
(Berlyne \& Crozier, 1971) and the two experiments reported here, we find that comparable proportions of more complex choices occur after near darkness and silence, after exposure of the patterns that repeatedly follow the choice, after light music, and after white noise. Significantly lower proportions of more complex choices occur after exposure of colored pictures of tourist attractions and after excerpts from a recorded story. What distinguishes the two sets of prechoice conditions can hardly be arousal value, since white noise is included in the former set. On the other hand, the conditions belonging to the second set contain symbolic content that require perceptual and intellectual effort to analyze them, assimilate them, and make sense of them. The results favor the conclusion that the strength of the tendency to seek exposure to relatively complex stimulus material varies inversely with the level of exteroceptive information processing just before the choice. This could likewise account for the findings of Leckart et al (1970).

\section{REFERENCES}

BERLYNE, D. E., \& CROZIER, J. B. Effects of complexity and pre-choice stimulation on exploratory choice. Perception \& Psychophysics, 1971, 10. 242-246.

BERLYNE, D. E., \& LEWIS, J, L. Effects of heightened arousal on human exploratory behavior. Canadian Journal of Psychology, 1963, 17, 398-411.

HAYWOOD, H.C. \& WACHS.T. D. Effects of arousing stimulation upon novelty preference in rats. British Journal of Psychology, 1967, 58, 77-84.

LECKART, B. T., LEVINE, J. R. GOSCINSKI, C.. \& BRAYMAN, W. Duration of attention: The perceptual deprivation effect. Perception \& Psychophysics, 1970, 7, 163-164.

MCLEAN, P. D. Induced arousal and time of recall as determinants of paired-associate recall. British Journal of Psychology, $1969,60,57-62$.

PODVOLL, E. M., \& GOODMAN, S. J. Averaged neural electrical activity and arousal. Science, 1967, 155, 223-225.

THAYER, R., ANDERSON, j.. WHITE, V. \& SPADONE, A. Stimulus-seeking behavior and activation level as a function of white noise. Paper read to IVPA meeting, Los Angeles, April 1970. 